\title{
Modelowanie łuku spawalniczego o zmiennej długości kolumny plazmowej
}

\author{
Modeling of welding arc with variable \\ plasma column length
}

\section{Streszczenie}

W artykule opisano modele Cassiego-Bergera i Kułakowa łuku elektrycznego o zaburzanej długości kolumny plazmowej. Przedstawiono nowy model hybrydowy łuku słuszny w zakresach słabych i silnych prądów, a także wyniki symulacji procesów w obwodzie $z$ tym modelem, $z$ wymuszeniem prądowym okresowym i z zaburzeniem monotonicznym. Wykazano też efektywność wykorzystania tego modelu łuku do obliczania urządzeń spawalniczych.

\section{Abstract}

The article describes simple Cassie-Berger and Kulakov models of electrical arc with disturbed plasma column length. A new hybrid model of the arc have been created, correct in weak as well as strong current ranges. Simulation results of processes in a circuit with this model have been presented, with periodic current forcing and monotonic disturbance. Effectiveness of using this arc model to calculate welding devices has been demonstrated in numerical way.

\section{Wstęp}

Do podstawowych zadań układów regulacji wielu urządzeń spawalniczych należą odpowiednia zmiana długości łuku i jej stabilizacja w procesach cięcia i spajania. Ręczne lub automatyczne oddziaływanie na elektrodę prowadzi nie tylko do zmiany mocy rozpraszanej, ale także wpływa na rozkład strumieni cieplnych (radiacyjnych i konwekcyjnych) w kolumnie plazmowej [1]. Choć w krótkim łuku spawalniczym zasadnicze znaczenie mają efekty cieplne w obszarach przyelektrodowych, to na skutek pochłaniania własnego promieniowania cieplnego przez optycznie grubą plazmę formowanie strumieni cieplnych, kierowanych do jeziorka spawalniczego i do elektrody, odbywa się we wnętrzu krótkiej kolumny plazmowej [2].

Krótka kolumna plazmowa łuku spawalniczego ze strugami elektrodowymi zjonizowanych par metali

Dr hab. inż. Antoni Sawicki, prof. PCz

- Polite-chnika Częstochowska. wyróżnia się zmiennością charakterystyk elektrycznych na skutek różnego składu chemicznego atmosfery gazowo-parowej oraz różnych oddziaływań gazodynamicznych i magnetycznych. Oddziaływania te wywołują przede wszystkim zmiany długości kolumny plazmowej. Praktyczne zmierzenie tej długości jest bardzo trudne. Tylko w przypadkach urządzeń plazmowych z łukiem stabilizowanym (np. ściankami kanału lub przepływem gazowym) można podwyższyć dokładność pomiarów.

Rodziny charakterystyk napięciowo-prądowych $U(I, L)$ stanowią podstawę tworzenia modeli matematycznych łuku potrzebnych do sterowania strumieniami energii i zapewnienia stabilności wyładowania w urządzeniach spawalniczych i elektrotermicznych. W takich przypadkach posługiwanie się modelami stacjonarnymi łuku o stałej długości może prowadzić do znacznych niedokładności w symulowaniu procesów elektrycznych. Dotyczy to przede wszystkim stanów startu i stopu oraz specjalnych technologii spawania (z elektrodą wibrującą CMT - Cold Metal Transfer, czy TIG z łukiem odchylanym w polu magnetycznym). 


\section{Modele łuku elektrycznego o zmiennej długości kolumny plazmowej}

Od początku ubiegłego wieku podejmowano liczne próby analitycznego opisu wpływu zmian długości łuku na jego charakterystyki elektryczne statyczne [3]. Najbardziej ogólną zależność podał Nottingham:

$$
U=A+B l+\frac{C+D l}{I^{n}}
$$

gdzie: $A, B, C, D, n$ - współczynniki i wykładnik aproksymacji określane na podstawie danych eksperymentalnych.

Szczególne przypadki tego wzoru uzyskali Ayrton, Steinmetz, Browne i inni. Jak z niego widać, składnik napięcia łuku, który nie zależy ani od prądu, ani od długości kolumny, to suma przyelektrodowych spadków napięcia. Zależy ona od rodzaju materiału, kształtu i stanu cieplnego elektrod (zwłaszcza katody), ciśnienia i składu chemicznego środowiska gazowego. Wrażliwość charakterystyk statycznych na zmiany długości kolumny prowadzi do utworzenia rodziny charakterystyk dynamicznych napięciowo-prądowych. Ich opis jest jednak bardziej złożony ze względu na inercję procesów cieplnych, wynikających nie tylko ze zmian prądu, ale także z przebudowy kolumny. Jeśli zmiany długości łuku są niewielkie lub odbywają się z małą prędkością, to wtedy dla wygody obliczeń i w zgodzie z oczekiwaną dokładnością aproksymacji często wykorzystuje się modele Cassiego i Mayra, przyjmując ich parametry jako wielkości stałe. W przypadkach dużych względnych zmian długości łuku lub dużej prędkości wydłużania lub skracania kolumny założenia te mogą prowadzić do znacznych błędów modelowania i symulowania.

Modyfikację równania Cassiego, uwzględniająca zmiany długości łuku, podał Berger [4]. Jego równanie ma postać konduktancyjną:

$$
\frac{1}{g} \frac{d g}{d t}=\frac{1}{\theta_{C B}}\left(\frac{u_{k o t}^{2}}{u_{C}^{2}(l)+\frac{1}{g} p_{v}\left(\frac{d l}{d t}\right)}-1\right)
$$

gdzie: $\theta_{C B}-$ stała czasowa modelu.

Ponieważ napięcie na łuku rośnie wraz ze wzrostem długości kolumny, to w [4] zaproponowano następujące podejście do określania składnika kwadratu napięcia modelu Cassiego-Bergera:

$$
u_{c}^{2}(l)=a l
$$

przy czym parametr a $\left[\mathrm{V}^{2} / \mathrm{m}\right]$ jest niemal stały w szerokim zakresie zmian prądu.
$Z$ kolei dodatkowa moc $p_{v}(d l / d t)$ jest określona zależnością [4]:

$$
p_{v}\left(\frac{d l}{d t}\right)=\left\{\begin{array}{l}
b_{1} \frac{d l}{d t}, \quad \text { jesli } \frac{d l}{d t}>0 \\
-b_{2} \frac{d l}{d t}, \quad \text { jesli } \frac{d l}{d t} \leq 0
\end{array}\right.
$$

Zmodyfikowane równania Cassiego-Bergera łuku rozciąganego i skracanego przyjmują więc postać konduktancyjną:

$$
\frac{1}{g} \frac{d g}{d t}=\frac{1}{\theta_{C B}}\left(\begin{array}{ll}
\frac{u_{k o l}^{2}}{a l+\frac{b_{1}}{g} \frac{d l}{d t}}-1, & \text { jesli } \frac{d l}{d t}>0 \\
\frac{u_{k o l}^{2}}{a l-\frac{b_{2}}{g} \frac{d l}{d t}}-1, & \text { jesli } \frac{d l}{d t} \leq 0
\end{array}\right)
$$

ale jeśli nie działają inne dodatkowe czynniki formujące przemiany energii plazmy, to w większości przypadków modelowania obwodów $z$ łukiem o zaburzanej długości (także skracanym) można przyjąć $b_{2}=0$.

Równanie Cassiego daje najlepsze rezultaty w zakresie silnych prądów wyładowania. Taką samą właściwość ma równanie Cassiego-Bergera. Nie może ono wystarczająco dokładnie odwzorowywać procesów w łuku o słabym prądzie, zwłaszcza w okolicach przejść prądu przez wartość zerową.

Kułakow zaproponował modyfikację znanego modelu łuku, wykorzystującego charakterystykę statyczną napięciowo-prądową [5]. Ten zmodyfikowany model I rzędu, uwzględniający zmiany długości kolumny, zapisany w postaci konduktancyjnej jest następujący:

$$
\frac{1}{g} \frac{d g}{d t}=\frac{1}{\theta_{M K}}\left[\frac{i}{g \cdot l \cdot E_{\text {stat }}(i)}-1\right]-\frac{1}{l} \frac{d l}{d t}
$$

gdzie: $E_{\text {stat }}(i)$ - charakterystyka statyczna natężenia pola elektrycznego; $\theta_{M K}-$ stała czasowa modelu Kułakowa. Do aproksymacji charakterystyki $E_{\text {stat }}(i)$ wykorzystuje się najczęściej funkcję potęgową $E(I)=a l^{-b}[6]$.

Możliwości występowania zaburzeń długości łuku w różnych chwilach czasowych powodują potrzebę poszukiwania modeli, które z odpowiednio wysoką dokładnością będą odwzorowywać przebiegi wielkości elektrycznych w zakresach słabych i silnych prądów. Na podstawie podejścia TWV (King-Jet Tsenga, Yaoming Wanga, D. Mahinda Vilathgamuwy [7]) zmodyfikowany model hybrydowy kolumny łuku, uwzględniający zmiany jego długości, kojarzy modele (5) i (6) za pomocą odpowiedniej funkcji wagowej $\varepsilon(i)$. Ma on postać:

$$
\frac{1}{g} \frac{d g}{d t}=\frac{1}{\theta_{B K}}\left\{[1-\varepsilon(i)] \frac{u_{k o l}^{2}}{u_{C}^{2}(l)+\frac{1}{g} p_{v}\left(\frac{d l}{d t}\right)}+\varepsilon(i) \frac{i}{g \cdot l \cdot E_{s t a t}(i)}-1\right\}-\varepsilon(i) \frac{1}{l} \frac{d l}{d t}
$$

gdzie $\theta_{B K}$ jest zastępczą stałą czasową łuku określaną z danych eksperymentalnych. Wprowadzono tutaj oznaczenie:

$$
\varepsilon(i)=\exp \left(-\frac{i^{2}}{I_{0}^{2}}\right)
$$


gdzie: $I_{0}$ - wartość prądu granicznego między modelami Cassiego-Bergera a Kułakowa. W tym przypadku aproksymacja funkcji $E_{\text {stat }}(i)$ powinna być najbardziej dokładna w zakresie słabych prądów. Silnym prądom odpowiada stała wartość napięcia $u_{c}(i)=$ const, zależna tylko od długości łuku.

Jeśli uwzględnimy zależności (3) i (4), podane przez Bergera, to na podstawie zależności (7) otrzymamy model:

$\frac{1}{g} \frac{d g}{d t}=\frac{1}{\theta_{B K}}\left\{[1-\varepsilon(i)]\left[\begin{array}{ll}\frac{u_{k d}^{2}}{a l+\frac{b_{1}}{g} \frac{d l}{d t}}, & \text { jesli } \frac{d l}{d t}>0 \\ \frac{u_{k o l}^{2}}{a l}, & \text { jesli } \frac{d l}{d t} \leq 0\end{array}\right]+\varepsilon(i) \frac{i}{g \cdot l \cdot E_{s t a t}(i)}-1\right\}-\varepsilon(i) \frac{1}{l} \frac{d l}{d t}(9)$

Jego implementację komputerową podano w opracowaniu [8].

Do symulacji procesów w obwodach urządzeń elektrotechnicznych, w których zmiany długości kolumny łukowej są stosunkowo powolne $(d l / d t \approx 0)$, wzór na uproszczony model hybrydowy kolumny łuku (7) przekształca się do postaci:

$$
\frac{1}{g} \frac{d g}{d t}=\frac{1}{\theta_{B K}}\left\{[1-\varepsilon(i)] \frac{u_{k o l}^{2}}{u_{c}^{2}(l)}+\varepsilon(i) \frac{i}{g \cdot l \cdot E_{s t a t}(i)}-1\right\}
$$

Jeśli uwzględnimy zależności (3) i (4), podane przez Bergera, to z modelu (10) otrzymamy:

$$
\frac{1}{g} \frac{d g}{d t}=\frac{1}{\theta_{B K}}\left\{[1-\varepsilon(i)]_{\frac{u_{k l}}{a l}}^{2}+\varepsilon(i) \frac{i}{g \cdot l \cdot E_{\text {stat }}(i)}-1\right\}
$$

Pełny model łuku elektrycznego zawiera oprócz konduktancji kolumny także nieliniową konduktancję odwzorowującą przyelektrodowe spadki napięcia (przyanodowy $U_{A}$ i przykatodowy $U_{K}$ ). Taką dodatkową konduktancję $g_{E}$ określa zależność:

$$
g_{E}=\frac{i}{U_{K}+U_{A}}=\frac{i}{A}
$$

Jest ona połączona szeregowo z nieliniową konduktancją kolumny łukowej $g_{\text {kor }}$ Wtedy konduktancja wypadkowa wyznaczana jest ze wzoru

$$
\frac{1}{g}=\frac{1}{g_{E}}+\frac{1}{g_{k o l}}
$$

\section{Implementacja uproszczonego modelu łuku o zmiennej długości kolumny plazmowej w MATLAB-Simulink}

Praktyczne wykorzystanie modeli matematycznych łuku elektrycznego o zaburzanej długości kolumny plazmowej (Cassiego-Bergera, Kułakowa i hybrydowego) do symulowania stanów pracy urządzeń spawalniczych i elektrotermicznych może zostać znacznie ułatwione przez ich zaimplementowanie w popularnym programie MATLAB-Simulink.

$\mathrm{Na}$ rysunku 1 pokazano schemat makromodelu hybrydowego Cassiego-Bergera-Kułakowa łuku o zaburzanej długości kolumny. Opisuje go model matematyczny określony wzorem (11). Efekty symulacji procesów w obwodzie z łukiem (rys. 2), wymuszeniem elektrycznym okresowym i ze zmienioną długością kolumny pokazano na rysunkach 3 i 4 . W pierwszym przypadku uwzględniono sumę przyelektrodowych spadków napięcia $A=15 \mathrm{~V}$ oraz parametry prostego obwodu szeregowego zasilającego łuk: napięcie sinusoidalne $E=80 \mathrm{~V}, f=50 \mathrm{~Hz}, R=0,5 \mathrm{~W}, L=1,5 \mathrm{mH}$. Założone parametry modelu łuku były następujące: $\mathrm{a}=3600$ $\mathrm{V}^{2} / \mathrm{m} ; \theta_{C B}=3 \mathrm{e}-4 \mathrm{~s} ; I_{0}=5 \mathrm{~A}, I(t)=0,003+0,3 t$. Dane liczbowe z badań eksperymentalnych charakterystyk $E(I)$ cechują się bardzo dużym rozrzutem. To powoduje, że w literaturze zamieszczone są ich różne aproksymacje [6, 9]. Tutaj przyjęto zależność

$$
E_{\text {stat }}(\mathrm{I})=500 /^{-0,3}, \mathrm{~V} / \mathrm{cm}
$$

W drugim przypadku uwzględniono asymetrię przyelektrodowych spadków napięcia $A_{1}=13 \mathrm{~V}$ i $A_{2}=18 \mathrm{~V}$ oraz parametry prostego obwodu szeregowego

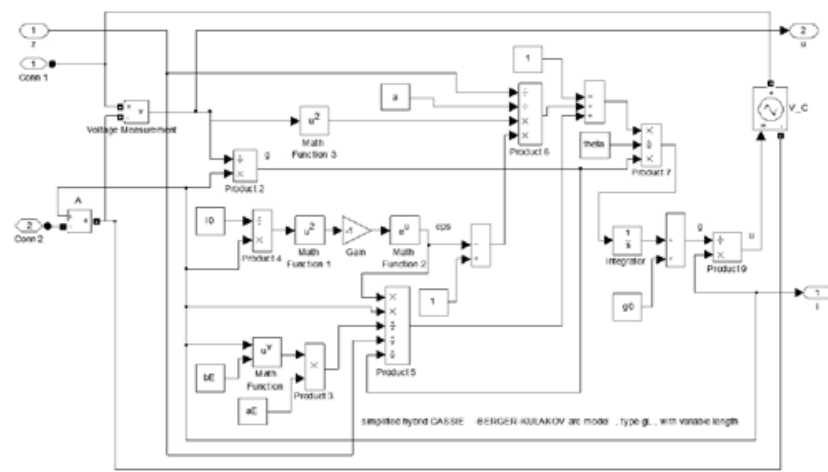

Rys. 1. Uproszczony makromodel hybrydowy Cassie-Bergera-Kułakowa łuku elektrycznego

Fig. 1. Simplified hybrid macro model of electrical arc acc. to. Cassiego-Berger-Kulakov

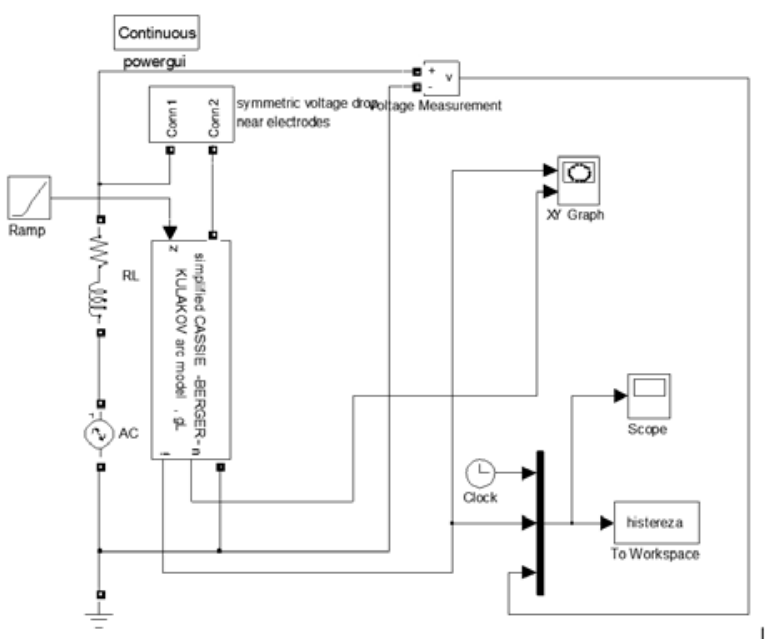

Rys. 2. Schemat symulowanego układu z modelem łuku Fig. 2. Diagram of simulated for model of the arc 
zasilającego łuk: napięcie wymuszajace o kształcie meandrycznym $E_{\text {max }}=115 \mathrm{~V}, E_{\min }=10 \mathrm{~V}$, współczynnik wypełnienia $70 \%, f=50 \mathrm{~Hz}, R=0,5 \Omega, L=2 \mathrm{mH}$. Założone parametry modelu łuku były takie jak poprzednio.

Ponieważ rozciąganiu łuku towarzyszy jednoczesne zmniejszanie prądu, to model hybrydowy wykładniczo samoistnie przełącza się z modelu

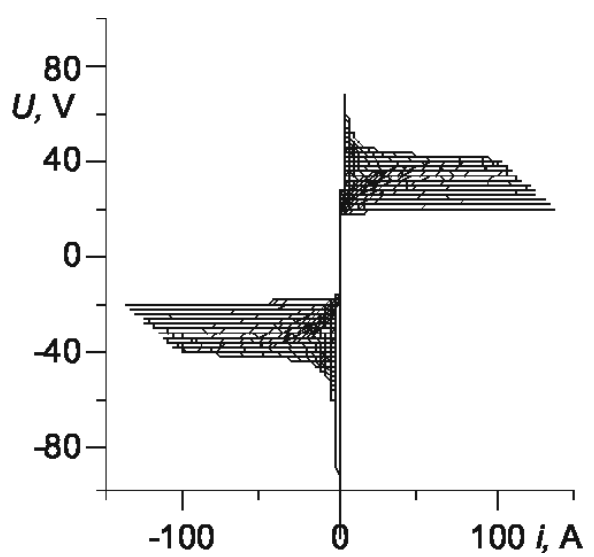

Rys. 3. Charakterystyki dynamiczne napięciowo-prądowe łuku ze zmienną długością kolumny $\mathrm{w}$ obwodzie $\mathrm{z}$ wymuszeniem napięciowym sinusoidalnym

Fig. 3. The dynamic characteristics of voltage-current of arc with length variable of column in the circuit with a sinusoidal voltage forcing
Cassiego na model Kułakowa. Na rysunkach 3 i 4 wyraźnie widać zmniejszanie się amplitudy prądu i narastanie amplitudy napięcia wraz ze stromymi odcinkami charakterystyk napięciowo-prądowych. W każdym przypadku rozciągania łuków prowadziły do ich zgaśnięcia, którym towarzyszyło powstanie znacznych przepięć.

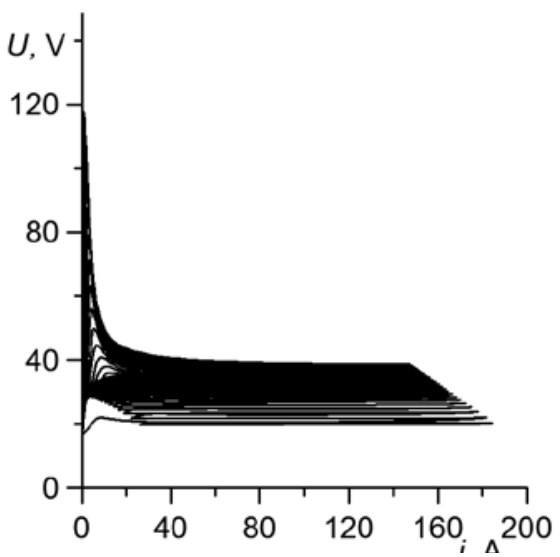

Rys. 4. Charakterystyki dynamiczne napięciowo-prądowe łuku ze zmienną długością kolumny w obwodzie $z$ wymuszeniem impulsowym Fig. 4. The dynamic characteristics of voltage-current of arc with length variable of column in a circuit with pulse forcing

symulowanie procesów elektrycznych w obwodach urządzeń spawalniczych w zakresach słabych i silnych prądów.

Adekwatność modelu hybrydowego Cassiego-Bergera-Kułakowa jest niezależna od chwil (lub faz) działania zaburzeń długości łuku.

\section{Literatura}

[1] Krouchinin A.M., Sawicki A.: A theory of electrical arc heating. The Publishing Office of Technical University of Częstochowa, Czestochowa 2003.

[2] Jones R.T., Reynolds Q.G., Curr T.R., Sager D.: Some myths about DC arc furnaces. Southern African Pyrometallurgy 2011, Edited by R.T. Jones \& P. den Hoed, Southern African Institute of Mining and Metallurgy, Johannesburg, 6-9 March 2011.

[3] Farzaneh M., Chisholm W.A.: Insulators for Icing and Polluted Environments. Wiley 2009.

[4] Berger S.: Mathematical approach to model rapidly elongated free-burning arcs in air in electric power circuits, ICEC 2006 6-9 June 2006, Sendai, Japan, 2006.

[5] Математические методы исследования динамики и проблемы управления низкотемпературной плазмой. Низкотемпературная плазма, том 2. Изд-во Наука, Новосибирск 1991.
[6] Залесский А.М.: Основы теории электрических аппаратов. Изд-во Высшая школа, Москва 1974.

[7] King-Jet Tseng, Yaoming Wang, D. Mahinda Vilathgamuwa: An Experimentally Verified Hybrid Cassie-Mayr Electric Arc Model for Power Electronics Simulations. IEEE Transactions on Power Electronics, 1997, vol. 12, no. 3, s. 429-436.

[8] Sawicki A.: Modelowanie łuku elektrycznego o zaburzanej długości kolumny plazmowej. Śląskie Wiadomości Elektryczne 2012 , nr 1 s. 9-17.

[9] Hemmatjou H.: Modeling of ac arc inside wet snow. Universite du Quebec, October 2006.

Praca naukowa finansowana przez MNiSW ze środków na naukę w latach 2010-2013 jako projekt badawczy Nr N N511 305038. 